\title{
Enhanced osteoinduction of electrospun scaffolds with assemblies of hematite nanoparticles as a bioactive interface
}

This article was published in the following Dove Medical Press journal: International Journal of Nanomedicine

\author{
Shanshan $\mathrm{Ma}^{1, *}$ \\ Zibin Wang ${ }^{2, *}$ \\ Yu Guo' \\ Peng Wang ${ }^{3}$ \\ Zukun Yang' \\ Liping Han' \\ Jianfei Sun ${ }^{4}$ \\ Yang $\mathrm{Xia}^{1,4}$
}

'Jiangsu Key Laboratory of Oral Diseases, Nanjing Medical University, Nanjing, Jiangsu 210029, China;

${ }^{2}$ Analysis and Test Center, Nanjing Medical University, Nanjing,

Jiangsu 21II66, China; ${ }^{3}$ Department

of Sports Medicine and Adult

Reconstructive Surgery, Drum

Tower Hospital Affiliated to Medical

School of Nanjing University, Nanjing,

Jiangsu 210008, China; ${ }^{4}$ Jiangsu

Key Laboratory for Biomaterials and Devices, School of Biological

Science and Medical Engineering,

Southeast University, Nanjing,

Jiangsu 210096 , China

*These authors contributed equally to this work

Correspondence: Yang Xia Jiangsu Key Laboratory of Oral Diseases, Nanjing Medical University, No. 136, Hanzhong Road, Nanjing, Jiangsu 210029, China

Email xiayang@njmu.edu.cn

Jianfei Sun

Jiangsu Key Laboratory for Biomaterials and Devices, School of Biological Science and Medical Engineering, Southeast University, Dingjiaqiao 87, Nanjing, Jiangsu 210096, China

Email sunzaghi@seu.edu.cn
Purpose: Electrospun scaffolds have been studied extensively for their potential use in bone tissue engineering. However, their hydrophobicity and relatively low matrix stiffness constrain their osteoinduction capacities. In the present study, we studied polymer electrospun scaffolds coated with hydrophilic hematite nanoparticles ( $\alpha$ FeNPs) constructed using layer-by-layer (LbL) assembly to construct a bioactive interface between the scaffolds and cells, to improve the osteoinduction capacities of the scaffolds.

Materials and methods: The morphology of the $\alpha$ FeNPs was assessed. Surface properties of the scaffolds were tested by X-ray photoelectron spectroscopy (XPS), surface water contact angle, and in vitro protein adsorption test. The stiffness of the coating was tested using an atomic force microscope (AFM). In vitro cell assays were performed using rat adipose-derived stem cells (ADSCs).

Results: Morphology characterizations showed that $\alpha$ FeNPs assembled on the surface of the scaffold, where the nano assemblies improved hydrophilicity and increased surface roughness, with increased surface stiffness. Enhanced initial ADSC cell spread was found in the nano assembled groups. Significant enhancements in osteogenic differentiation, represented by enhanced alkaline phosphatase (ALP) activities, elevated expression of osteogenic marker genes, and increased mineral synthesis by the seeded ADSCs, were detected. The influencing factors were attributed to the better hydrophilicity, rougher surface topography, and harder interface stiffness. In addition, the presence of nanoparticles was believed to provide better cell adhesion sites.

Conclusion: The results suggested that the construction of a bioactive interface by LbL assembly using $\alpha$ FeNPs on traditional scaffolds should be a promising method for bone tissue engineering.

Keywords: layer-by-layer assembly, osteogenesis, nanotechnology, bone tissue engineering, surface, $\alpha$ FeNPs

\section{Introduction}

Stem cells and scaffolds are two key factors in bone tissue engineering. ${ }^{1,2}$ As one of the most important types of scaffolds, electrospun scaffolds have been investigated extensively in recent year. ${ }^{3-5}$ They are produced by an electrospinning process, and comprise non-woven, three-dimensional, porous, and nano-scaled fiber-based matrixes. Their structure can mimic the extracellular matrix (ECM) that surrounds cells to provide mechanical support and regulate cell activities. Therefore, electrospun scaffolds have the potential to replace the natural ECM until the host cells can repopulate and resynthesize a new natural matrix. ${ }^{6}$ In bone tissue engineering, the osteoinduction of submit your manuscript Dovepress $5 y$ in 0 
stem cells on electrospun scaffolds is crucial for final bone regeneration effects. ${ }^{?}$

Commonly used electrospun matrix materials are polyesters, including polycaprolactone (PCL), polyglycolic acid (PGA), polylactic acid (PLA), and their copolymers, poly (D, L-lactide-coglycolide) (PLGA). ${ }^{8-10}$ These polymers are biodegradable, with excellent biocompatibility. However, their other properties, such as low hydrophilicity and low matrix stiffness, make them suboptimal for cellular adhesion and osteogenic differentiation. ${ }^{11}$ Cells always adhere to and interact with the surface of the electrospun scaffold. The cells commit to the lineage specified by the substrate elasticity, in addition to the effects of the substrates' chemical groups. ${ }^{12-14}$ In this sense, the scaffolds provide microenvironments that are important for stem cell lineage specification. The surfaces of the scaffolds work as an interface between the cells and the scaffolds, and thus play an important role in inducing osteogenic differentiation of stem cells. Therefore, many surface modification methods have been used to improve the surface properties of the scaffolds. ${ }^{5,15-18}$ A rigid interface with a micro-nano surface topography that mimics collagenous bone would favor cellular osteogenic differentiation. ${ }^{12-14,19,20}$

The introduction of nanotechnology and interface tissue engineering promises to allow the development of systems with gradients in biomaterials properties that encourage the differentiation of multiple cell phenotypes and subsequent tissue development. ${ }^{21-23}$ In addition, layer-by-layer (LbL) assembly provides a versatile method to form multilayers, based on alternative adsorption of oppositely charged polyelectrolytes, nanoparticles, and macromolecules on charged substrates. ${ }^{24}$ The assemblies can form uniform coatings on substrates of any dimension and topography. In comparison with other nano composite scaffold fabrication methods, such as dip-coating and co-electrospinning, LbL assembly is advantageous in that the surface morphology and roughness can be finely tuned by the assembly cycles. Therefore, it has been used widely to immobilize bioactive substances on scaffold surfaces. Moreover, the nanoparticles would be all exposed on the surfaces, while maintaining the original structure of the scaffolds, eg, the porous structure. Recently, LbL was reported to be applied in scaffold modification for bone tissue engineering. ${ }^{25}$

Among the many types of nanomaterials used for biomedical applications, iron oxide nanoparticles (IONPs) are promising to enhance the osteogenic differentiation of stem cells, ${ }^{26-28}$ and can provide transduction of dynamic mechanical stimulation, which is required for bone formation. ${ }^{29}$ IONPs have been used with various polymers in the electrospinning process. They exist in many forms in nature, namely magnetite $\left(\mathrm{Fe}_{3} \mathrm{O}_{4}\right)$, hematite $\left(\alpha-\mathrm{Fe}_{2} \mathrm{O}_{3}\right)$, and maghemite $\left(\gamma-\mathrm{Fe}_{2} \mathrm{O}_{3}\right)$. Maghemite, with excellent superparamagnetic properties, is the most studied form. ${ }^{27,28}$ However, hematite nanoparticles $(\alpha$ FeNPs) are the easiest to synthesize because they are the end products of the transformation of other iron oxide forms and are extremely stable under environmental conditions. ${ }^{30,31}$ Hematite is an oxide with a weak ferromagnetic or anti-ferromagnetic behavior at room temperature..$^{30,31}$ Their abundance, low cost, low toxicity, excellent chemical stability, and tunable optical and magnetic properties, has meant that $\alpha$ FeNPs have attracted considerable attention in catalytic reactions, paint manufacturing, lithium-iron batteries, gas sensors, biomedical applications, magnetic storage devices, and photoelectron chemical splitting of water. ${ }^{32}$ In addition, $\alpha F e N P s$ have been used to improve the initial flowing properties of calcium phosphate cement, ${ }^{33}$ which is widely used in dental and orthopedic applications, eg, bone fractures, bone tumors, osteoporosis, and craniofacial affections. The addition of $\alpha$ FeNPs into the powder phase of an $\alpha$-tricalcium phosphate (TCP)-based cement improved both the initial injectability and maximum compressive strength of the cement, without affecting its physico-chemical setting reactions or cytocompatibility. The reasons may lie in that the addition of $\alpha$ FeNPs, which can act as nanometer rollers between the bigger $\alpha$-TCP particles, lubricated the hydrodynamic interaction between $\alpha$-TCP particles. ${ }^{33}$ Therefore, $\alpha \mathrm{FeNPs}$ are very promising for bone engineering.

Stem cells are another important factor in bone tissue engineering. Adipose-derived stem cells (ADSCs) are excellent multipotent stem cells that can be readily induced into several types of cells, such as adipocytes, chondrocytes, myoblasts, and osteoblasts. ${ }^{34}$ Moreover, ADSCs are easy to handle and obtain. Therefore, ADSCs were chosen as the seed cells in the present study.

In this study, electrospun scaffolds were coated with $\alpha \mathrm{FeNPs}$ using LbL assembly to construct a bioactive interface. The objective was to investigate the synergistic effects of micro-scale surface topography and increased matrix rigidity from the nano assembly on osteogenic induction of the electrospun scaffold. The hypotheses were that: 1) This bioactive interface would improve the hydrophilicity and the surface roughness of the electrospun scaffolds; 2) The $\alpha \mathrm{FeNP}$ assemblies would enhance the interface stiffness, thus benefitting the osteogenic differentiation of stem cells; and 3) This bioactive interface would provide better sites for cell adhesion, thereby promoting the osteogenic differentiation of stem cells. 


\section{Materials and methods \\ Preparation of electrospun scaffolds}

The preparation of electrospun scaffolds was the same as described previously. ${ }^{10}$ Briefly, $0.45 \mathrm{~g}$ of PLGA (75/25, average $\mathrm{Mw}=12 \mathrm{kDa}$; Jinan Daigang Biomaterial, Jinan, China), and $0.45 \mathrm{~g}$ of PCL (average $\mathrm{Mw}=11 \mathrm{kDa}$; Jinan Daigang Biomaterial) were dissolved in $7.3 \mathrm{~g}$ trifluoroethanol, and stirred overnight. For electrospinning, the polymer solution was placed in a syringe pump with a $0.4-\mathrm{mm}$ diameter metal needle (Jianpai, Jintan, China) connected to a high-voltage power supply $(16 \mathrm{kV})$. The injection rate was $0.8 \mathrm{~mL} / \mathrm{h}$. A nanofibrous structure was formed on the aluminized collecting plate, which was placed $15 \mathrm{~cm}$ from the needle tip. The obtained membranes were dried in a vacuum freeze-drier (Huaxing Technology, Develop Co Ltd, Beijing, China) for 72 hours, and stored at room temperature for further use.

\section{Preparation and characterization of surface modified $\alpha$ FeNPs}

The $\alpha$ FeNPs were bought from Aladdin Chemicals (Shanghai, China) and were surface modified with dimercaptosuccinic acid (DMSA, Aladdin Chemicals). Briefly, the $\mathrm{pH}$ of $\alpha \mathrm{FeNPs}$ solution was adjusted to 2.7 , and the concentration adjusted to $1 \mathrm{mg} / \mathrm{mL}$. DMSA was dissolved in dimethyl sulfoxide (DMSO, Aladdin Chemicals) at $1 \mathrm{~g}: 36 \mathrm{~mL}$. Then, the mixture was added into the system to react for 5 hours $(\alpha F e N P s$ : DMSA $=4: 1$, $\mathrm{w} / \mathrm{w})$. Vigorous stirring was needed during the reaction. Then, the $\mathrm{pH}$ of the mixture was adjusted to neutral. Finally, impurities were removed by dialysis and centrifugation. ${ }^{35}$

The colloidal suspension of nanoparticles was observed using transmission electron microscopy (TEM, JEOL-7100, JEOL, Peabody, MA, USA). The magnetic properties were measured at room temperature by a vibrating sample magnetometer (VSM; Lakeshore 7470, Lake Shore Cryotronics, Lake Shore, CA, USA) in an applied magnetic field of up to $20 \mathrm{kOe}$, to determine saturation magnetization and hysteresis loops. VSM was calibrated using a standard reference (high purity nickel sphere), supplied with the instrument. The hydrodynamic diameters and zeta potential of the nanoparticles were measured using dynamic light scattering (DLS) in a particle size analyzer (Malvern Zetasizer Nano ZS90, Malvern, UK). Zeta potential was measured at neutral condition.

\section{LbL assembly of the nanoparticles}

The LbL approach was used to assemble $\alpha$ FeNPs onto electrospun scaffolds, resulting into two groups in the current study.
1) ES (control): untreated electrospun scaffolds;

2) $\alpha$ Fe-ES: $\alpha$ FeNPs-assembled electrospun scaffolds, using an $\alpha$ FeNPs solution $(2.55 \mathrm{mg} / \mathrm{mL})$.

Briefly, the coating procedure was as follows. First, the electrospun scaffolds were treated with nitrogen plasma for 30 seconds at $220 \mathrm{~V}$ and a current of 1.5-1.8 A to achieve a negative charge on the surface; the distance between the two electrodes was $55 \mathrm{~mm}$. Then, the nitrogen plasma-treated film was immersed into poly(Diallyldimethylammonium chloride) (PDDA) solution ( $2 \mathrm{mg} / \mathrm{mL}$ ) for 30 minutes to achieve a uniform surface charge for the successive positive charged polyelectrolyte, followed by rinsing at least twice with pure water. The positively charged electrospun scaffolds were then dipped in negatively charged nano $\alpha \mathrm{FeNP}$ solution at room temperature for 30 minutes, followed by two rinsing cycles. The last step was freeze-drying, which ensured the firm adhesion of the nanoparticles. The whole procedure was repeated four times to obtain a dense and uniform nano assembly.

\section{Morphological characterization of the scaffolds}

After thoroughly drying and sputter-coating with gold, the samples (ES, $\alpha \mathrm{Fe}-\mathrm{ES})$ were observed using scanning electron microscopy (SEM; S-3400N II, Hitachi, Tokyo, Japan). Ultra-thin sections were prepared for TEM (Tecnai G2 Spirit BioTWIN, FEI, Hillsboro, OR, USA) observation. The content of the nanoparticles on the electrospun fibers was measured using thermogravimetric analysis (TGA, Pyris 1 DSC, PerkinElmer, Waltham, MA, USA). The magnetic properties were measured at room temperature by a VSM.

Atomic force microscopy (AFM) imaging and force spectroscopy were performed using an Agilent 5500 (Agilent, Chandler, AZ, USA) "closed loop" AFM system with a sensored piezoelectric field (Agilent). AFM probes with sphere-shaped tips and Au coating on the reflective side of the pre-magnetically coated cantilever were used for AFM measurements. The tip's radius of the curvature was $8 \mathrm{~nm}$. The spring constant of the cantilever was tested as $0.1 \mathrm{~N} / \mathrm{m}$. The images and the force curves were obtained in air and were acquired by using an Agilent AAC mode AFM. The obtained AFM images were processed using the WSxM software. Before acquiring force spectroscopy data, the AFM cantilever spring constant was calibrated through the resonance frequency changes that were induced by a small mass. ${ }^{36}$ The Young's modulus was calculated using the Hertz model: ${ }^{37}$ 


$$
F=\frac{4 E R^{\frac{1}{2}} \delta^{\frac{3}{2}}}{3\left(1-v^{2}\right)},
$$

where $F$ is the loading force, $v$ is Poisson's ratio (assumed to be 0.5$), \delta$ is the indentation depth, $E$ is the elastic modulus, and $R$ is the radius of the tip ( $\mathrm{n}=4)$.

\section{Surface properties}

X-ray photoelectron spectroscopy (XPS) was acquired for scaffold samples before and after $\alpha$ FeNPs assembly using PHI 5000 VersaProbe (ULVAC-PHI Inc., Osaka, Japan) operating using monochromatic $\mathrm{Al} \mathrm{K}_{\alpha}(1,486.6 \mathrm{eV})$ to determine the surface chemical composition. Data analysis and evaluation were performed using CasaXPS software, version 2.3.15 (Casa Software Ltd., Teignmouth, UK). The binding energies for the collected photoelectrons were referenced using $\mathrm{C} 1$ seconds peak at $285 \mathrm{eV}$.

The wettability of the films was examined by measuring contact angles using the sessile drop technique with a contact angle meter (JC2000C2, Shanghai Zhongchen Powereach Company, China) (n=9).

\section{Protein adsorption}

Protein adsorption onto the films was determined to examine whether nano coating would change the protein adsorption. The sample (6 $\mathrm{mm}$ in diameter) was immersed in phosphatebuffered saline (PBS) for 2 hours. The samples then were immersed in a bovine serum albumin (BSA (4.5 g/L); Sigma-Aldrich, St Louis, MO, USA) solution at $37^{\circ} \mathrm{C}$ for 12 hours. The disks then rinsed with fresh PBS, immersed in $1 \%$ sodium dodecyl sulfate (SDS)/PBS solution, and sonicated at room temperature for 20 minutes to completely detach the BSA from the scaffold. ${ }^{38}$ A BCA Protein Assay Kit (Beijing Leagene Biotechnology Co., Ltd, China) was used to determine the amount of BSA adsorbed onto the sample $(n=9)$.

\section{In vitro cell assay}

\section{Cell culture}

OriCell Sprague Dawley rat ADSCs were purchased from Cyagen Biosciences (Guangzhou, China). Cells at passage 3-5 were used. Cell adhesion and proliferation tests were done using complete medium for Sprague Dawley rat ADSCs (Cyagen Biosciences). Dexamethasone $\left(10^{-7} \mathrm{M}\right)$, $50 \mu \mathrm{M}$ ascorbate-2-phosphate, and $10 \mathrm{mM} \beta$-glycerol phosphate (Sigma-Aldrich) were supplemented into the complete medium to make osteogenic medium, and cell osteogenic differentiation tests were done using osteogenic medium.

\section{Cell adhesion on the scaffolds}

The morphology of the ADSCs attached to the films was observed using confocal laser scanning microscopy (CLSM; Zeiss-LSM510, Carl Zeiss, Oberkochen, Germany) after cultivation for 6 hours and 24 hours. For CLSM, the samples were washed with $1 \times \mathrm{PBS}$, fixed with $3.7 \%$ paraformaldehyde for 30 minutes at room temperature, and then permeabilized with $0.25 \%$ Triton X-100/PBS for 3 minutes. After incubation with rhodamine phalloidin (1:200 dilution; Cytoskeleton, Inc., Denver, CO, USA) for 30 minutes, the samples were rinsed five times with $1 \times \mathrm{PBS}$. The samples were then incubated with 4',6-diamidino-2-phenylindole (1:2,000 dilution; DAPI, Beyotime, Shanghai, China) for 30 seconds, rinsed fives times with $1 \times \mathrm{PBS}$, and observed by CLSM. The incubation was performed in the dark at room temperature. Three images were taken at random locations of each sample. Ten images of each group were analyzed by Image-Pro Plus 6.0 software. The cell spreading area was calculated as:

$$
S=\frac{S_{\text {total }}}{N_{\text {cell }}},
$$

where $S_{\text {total }}$ is the total cell spreading area on the image, and $N_{\text {cell }}$ is the number of cells.

A cell counting kit-8 (CCK-8, Beyotime) was used to evaluate the adhered cell ratio normalized by the culture well control at 6 hours after seeding $(n=4): 39$

\section{Cell adhesion ratio}

$$
=\frac{\text { Optical density }(\mathrm{OD}) \text { value of scaffold group }}{\text { OD value of culture well control }} \times 100 \%
$$

\section{Cell morphology and proliferation}

At 1, 4, 7, and 10 days, the cell number was measured using the same CCK- 8 kit. After a 2 hours incubation in the dark, the $\mathrm{OD}$ at $450 \mathrm{~nm}$ was determined using an enzyme-linked immunosorbent assay (ELISA) plate reader (Titertek, Helsinki, Finland) ( $\mathrm{n}=4)$.

Two-day samples of ES and $\alpha$ Fe-ES were fixed with 2.5\% glutaraldehyde ( $\mathrm{pH}$ 7.4) for 30 minutes, and dehydrated using a gradient series of ethanol:distilled water (30:70, 50:50, 90:10, and 100:0). The sample was freeze-dried under a 
vacuum and sputter-coated with gold. Cell morphology on the films was observed using SEM.

\section{Cell differentiation}

Alkaline phosphatase activity (ALP)

At 4,7 , and 14 days, cells on ES and $\alpha$ Fe-ES were lysed and assayed for their ALP activity using an Alkaline Phosphatase Assay kit (NanJing JianCheng Bioengineering Institute, China). ALP activity was normalized by the total protein content of each sample, which was quantified using a Leagene BCA Protein Assay Kit $(n=4)$.

\section{Quantitative real-time reverse transcription polymerase chain reaction ( $\mathrm{qRT}-\mathrm{PCR}$ )}

At 7 and 14 days after cell seeding, total RNA was extracted using the TRIzol reagent (Invitrogen, Carlsbad, CA, USA) according to the manufacturer's protocols. The genes assessed included Alp, collagen type I (Coll), runt-related transcription factor 2 (Runx2), osteocalcin (Ocn), and ironsulfur cluster assembly protein 1 (Iscal). Glyceraldehyde 3-phosphate dehydrogenase ( Gapdh) was used as the housekeeping gene. The sequences of the primers are listed in Table 1. The RNA concentration and purity were detected using a NanoVue Plus spectrophotometer (GE Healthcare, Piscataway, NJ, USA). PrimeScript RT reagent kit (Takara Bio Co., Ltd., Otsu, Japan) was used in the reverse transcription reactions. qRT-PCR reactions were performed using an ABI 7300 Real-time PCR System (Applied Biosystems, Foster City, CA, USA): a 5 minutes denaturation step at $95^{\circ} \mathrm{C}$, followed by 40 cycles of 10 seconds at $95^{\circ} \mathrm{C}$ and 31 seconds at $60^{\circ} \mathrm{C}$. Relative gene expressions of the cells on $\alpha \mathrm{Fe}-\mathrm{ES}$ were evaluated using the $2^{-\Delta \Delta C t}$ method and normalized by the cycle threshold $(\mathrm{Ct})$ of the housekeeping gene Gapdh in

Table I Real-time polymerase chain reaction primers used in this study

\begin{tabular}{|c|c|}
\hline Gene & Primer sequence \\
\hline Gapdh & $\begin{array}{l}\text { Forward: 5'-CCTTCCGTGTTCCTACCC-3' } \\
\text { Reverse: 5'-CAACCTGGTCCTCAGTGTAG-3' }\end{array}$ \\
\hline$A l p$ & $\begin{array}{l}\text { Forward: 5'-CGAGCAGGAACAGAAGTTTGC-3' } \\
\text { Reverse: 5'-GAATCCGACCCACGGAGG-3' }\end{array}$ \\
\hline Coll & $\begin{array}{l}\text { Forward: 5'-TGAGACAGGCGAACAAGGTGAC-3' } \\
\text { Reverse: 5'-GGACCAGCAGGACCACTATCG-3' }\end{array}$ \\
\hline Runx2 & $\begin{array}{l}\text { Forward: 5'-TTCGTCAGCGTCCTATCAGTTCC-3' } \\
\text { Reverse: 5'-CCATCAGCGTCAACACCATCATTC-3' }\end{array}$ \\
\hline Ocn & $\begin{array}{l}\text { Forward: 5'-ACССТСТСТСТGСTCACTCTGC-3' } \\
\text { Reverse: 5'-CСТTAСTGСССТССTGCTTGG-3' }\end{array}$ \\
\hline Iscal & $\begin{array}{l}\text { Forward: 5'-TGTCCGAACCAGGGGCTGTA-3' } \\
\text { Reverse: 5'-AAGTGTTAGCTGTGCTTTCTTTTCG-3' }\end{array}$ \\
\hline
\end{tabular}

triplicate. The Ct of ADSCs cultured on ES served as their own calibrator at each determined test time point $(n=4)$.

\section{Mineral synthesis by ADSCs on scaffolds}

After 21 day's co-culture, the scaffolds were stained with 2\% Alizarin Red S (ARS, Millipore, Billerica, MA, USA), which stained calcium-rich deposits made by the cells into a dark red color. The mineralized rate of the cells on $\alpha$ Fe-ES was performed by measuring the absorbance at $550 \mathrm{~nm}$ after eluting the ARS deposit with 10\% cetylpyridinium chloride (Sigma-Aldrich). The amount of synthesized minerals on ES served as the calibrator $(n=6)$.

\section{Detection of the interaction of ADSCs with the scaffolds}

To detect whether there were nano materials internalized by ADSCs, cell samples were prepared at 7 days after seeding. They were observed via TEM (Tecnai ${ }^{\mathrm{TM}}$ G2 Spirit Twin system, FEI).

\section{Statistical analysis}

All data were expressed as the mean value and standard deviation (SD). The SPSS statistical package (version 22.0; IBM Corp., Armonk, NY, USA) was used for the statistical analysis. Group comparisons were conducted using one-wayanalysis of variance (ANOVA) with Bonferroni post-hoc tests. Differences were considered significant if $P<0.05$, and highly significant if $P<0.01$.

\section{Results \\ Characterization of nanoparticles}

The morphology of the nanoparticles was examined by TEM. The nanoparticles were rod or spindle-like, with average dimensions of $10 \times 90 \mathrm{~nm}$, and were homogeneously distributed (Figure 1A).

The main parameters of the nanoparticles, as measured by a Malvern Zetasizer Nano ZS90, are shown in Table 2. The nanoparticles showed a low polydispersity Index (PDI), indicating a narrow size distribution. Thus, they were very homogeneous, which was consistent with TEM images. In addition, their surface was negatively charged.

The magnetic properties of the nano solution were investigated by observing the hysteresis loops of samples according to variations in the magnetic field. The $\alpha$ FeNPs displayed very weak magnetic behavior, indicated by the overlap magnetic hysteresis loop (Figure 1B). However, the $\alpha$ Fe-ES was not magnetic (Figure 1B). 
A

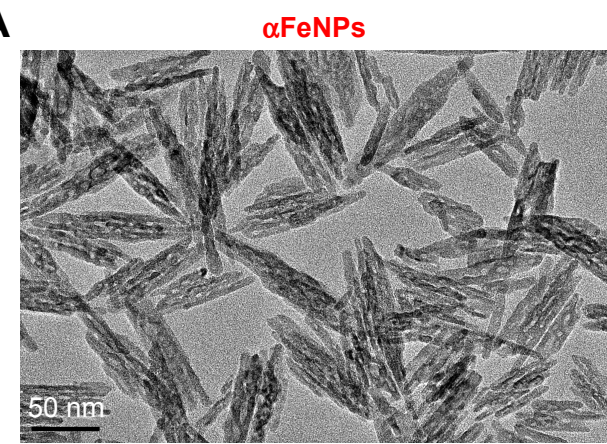

B

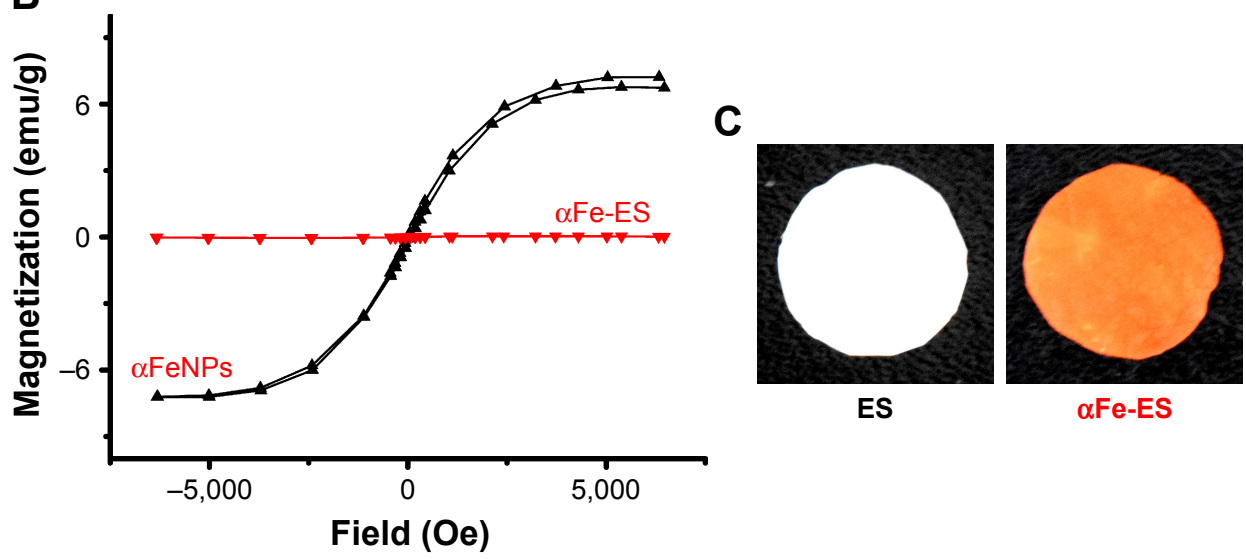

Figure I Sample characterization.

Notes: (A) TEM image of $\alpha$ FeNPs. (B) Hysteresis loops of $\alpha$ FeNPs and $\alpha$ Fe-ES, indicating weak superparamagnetism of $\alpha$ FeNPs, and non-magnetism of $\alpha$ Fe-ES. (C) Photos of fabricated $\alpha \mathrm{Fe}-\mathrm{ES}$ with assembled nanoparticles and the untreated ES control.

Abbreviations: $\alpha$ FeNP, hydrophilic hematite nanoparticle; $\alpha \mathrm{Fe}-\mathrm{ES}, \alpha \mathrm{FeNPs}$-assembled electrospun scaffold; ES, untreated electrospun scaffold; TEM, transmission electron microscopy.

The color of $\alpha \mathrm{Fe}$-ES was similar to that of the $\alpha \mathrm{FeNPs}$, presenting as dark brown (Figure 1C by camera). The color of the control ES was white.

\section{Characterization of nano assembled scaffolds}

SEM and TEM images of the two groups are shown in Figure 2. The SEM images showed that both scaffolds comprised randomly oriented fibers with diameters ranging from 0.6 to $1.5 \mu \mathrm{m}$ (Figure 2A and B). Three-dimensional pores between fibers were interconnected and distributed throughout the structure (Figure 2A). The fibers of the ES control group were smooth and clean (Figure 2A, C, and E). By contrast, the modified groups were much rougher, with the outer surface all coated with nanoparticle assemblies (Figure 2D). As confirmed by TEM cross-section images

Table 2 Main parameters of the hematite nanoparticles used in the present study (mean \pm SD)

\begin{tabular}{l|l|l|l}
\hline Sample & $\begin{array}{l}\text { Hydrodynamic } \\
\text { size }(\mathbf{n m})\end{array}$ & $\begin{array}{l}\text { Polydispersity } \\
\text { index (PDI) }\end{array}$ & $\begin{array}{l}\text { Zeta potential } \\
(\mathbf{m V})\end{array}$ \\
\hline$\alpha \mathrm{FeNPs}$ & $65.42 \pm 6.23$ & $0.215 \pm 0.047$ & $-29.12 \pm 0.64$ \\
\hline
\end{tabular}

(Figure 2F), rod-like nanoparticle assemblies were continuous around the fibers, forming a coating that was dense and homogenous. The thickness of the coating was about $100 \mathrm{~nm}$ (Figure 2F). These results proved that the nanoparticles were successfully assembled on the fibers. The coating increased the fiber diameter at some extent. However, it was too thin to affect the overall thickness of the bulk scaffold.

The morphology of the two groups was also detected by AFM (Figure 3). The ES control presented a striped structure because of the numerous fibers (Figure $3 \mathrm{~A}$ and $\mathrm{C}$ ). Comparatively, $\alpha$ Fe-ES was rougher (Figure 3B and D). However, it still maintained the typical stripe-like basal structure.

AFM was used to perform nano-indentation and determine the elastic modulus of the interface. Representative deflection curves of the electrospun scaffolds are shown in Figure 4A. $\alpha \mathrm{Fe}-\mathrm{ES}(1.37 \pm 0.11)$ had a higher micro-stiffness than ES $(0.77 \pm 0.08, P<0.01)$ (Figure 4B). The surface roughness was also measured by AFM. For ES, the rootmean-square (RMS) roughness was only $167 \pm 0.8 \mathrm{~nm}$, and it was increased to $342 \pm 1.2 \mathrm{~nm}$ for $\alpha \mathrm{Fe}$-ES.

TGA provided information on the quantity of nanomaterials assembled on the fibers. As shown in Figure 4C, similar 

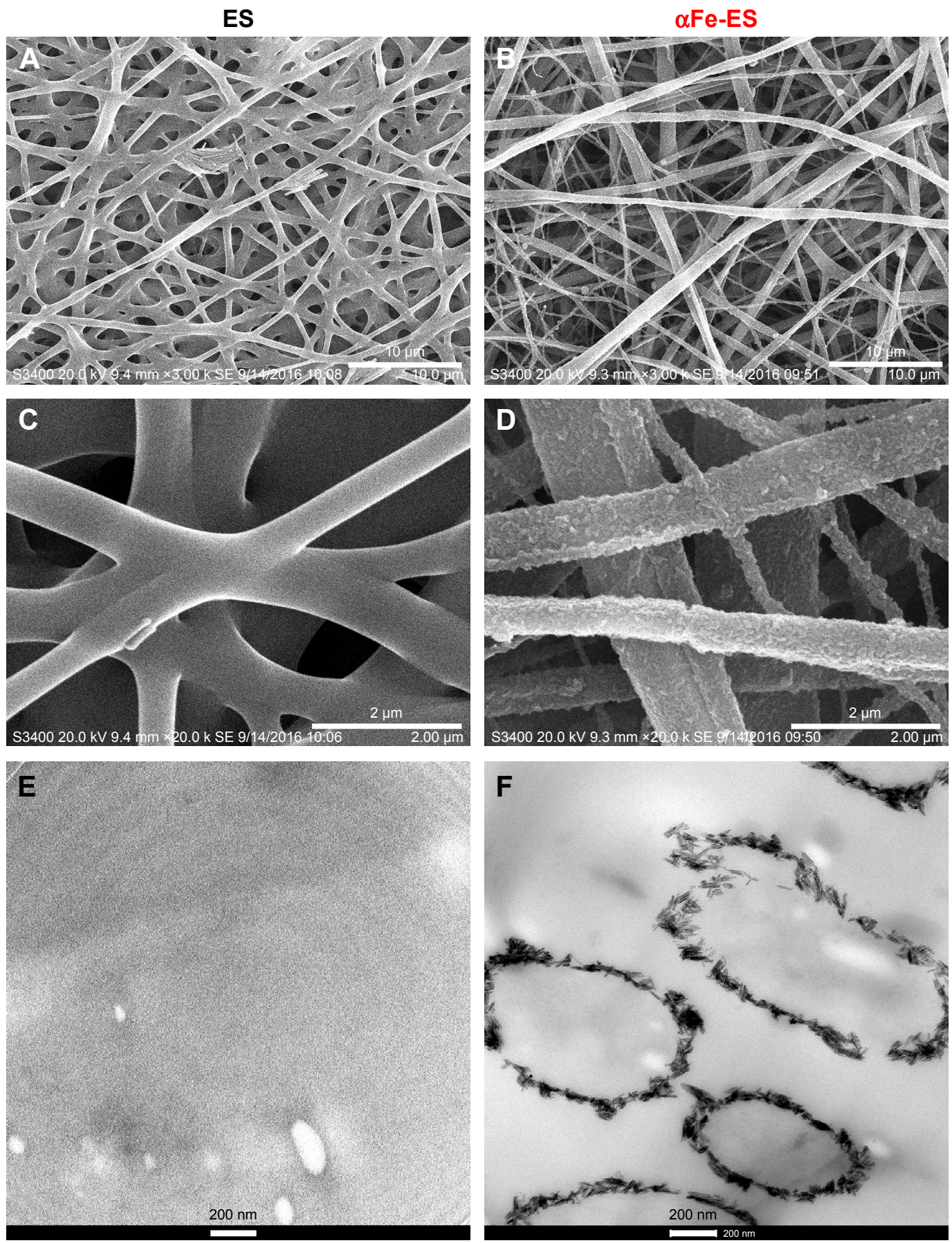

Figure 2 SEM (A-D) and TEM (E, F) images of the scaffolds: ES Control (A, C, E); $\alpha$ Fe-ES (B, D, F).

Note: The images present the morphology of the nano assemblies on the outer surface of the electrospun scaffolds.

Abbreviations: $\alpha$ FeNP, hydrophilic hematite nanoparticle; $\alpha$ Fe-ES, $\alpha$ FeNPs-assembled electrospun scaffold; ES, untreated electrospun scaffold; SEM, scanning electron microscopy; TEM, transmission electron microscopy.

behaviors were observed for all samples. The slight weight loss below $250^{\circ} \mathrm{C}$ was attributed to water removal, while the second weight loss at approximately $280^{\circ} \mathrm{C}-350^{\circ} \mathrm{C}$ was attributed to the decomposition of the PLGA polymer, and the third weight loss at approximately $350^{\circ} \mathrm{C}-400^{\circ} \mathrm{C}$ was attributed to the decomposition of the PCL polymer. Decomposition was finalized at approximately $500^{\circ} \mathrm{C}$. The remnant weight was $22.3 \%$ for $\alpha \mathrm{Fe}-\mathrm{ES}$, which demonstrating the amount of the nanomaterials assembled on the scaffolds. Therefore, the adhesion of $\alpha$ FeNPs over the surfaces did not enhance the thermal stability of the scaffold, because such a thin coating cannot affect the overall properties of the bulk material. 
A

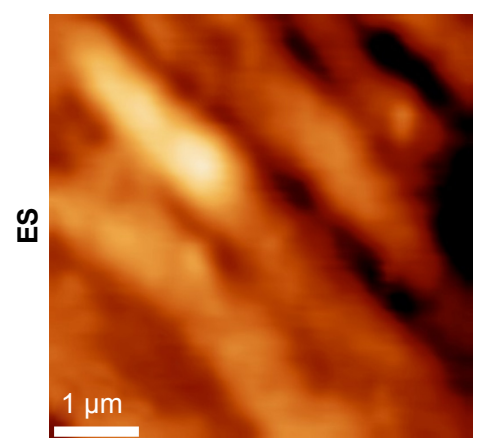

B

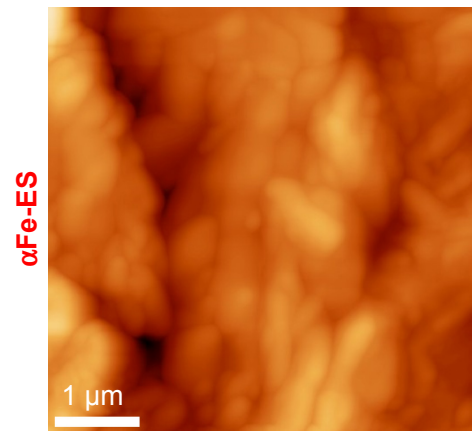

C

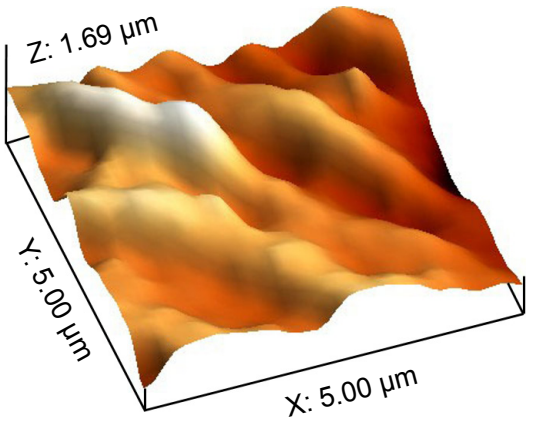

D

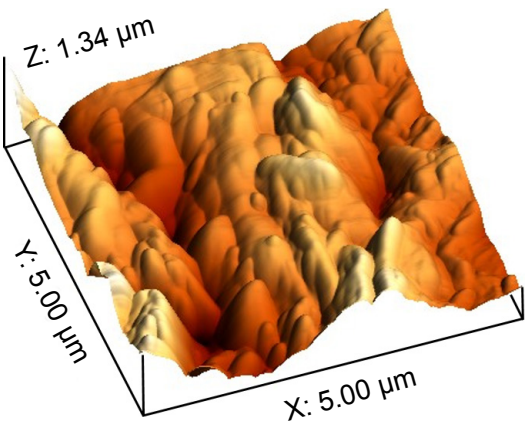

Figure 3 AFM images of ES and $\alpha F e-E S$. Two-dimensional AFM images of ES (A), and $\alpha F e-E S(B)$. Three-dimensional AFM reconstruction of ES (C) and $\alpha$ Fe-ES (D).

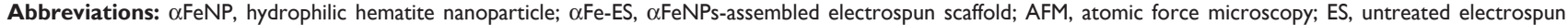
scaffold.

\section{Surface properties and protein adsorption}

XPS was employed to characterize the elemental surface composition of the scaffolds before and after $\alpha$ FeNPs assembly, respectively (Figure 4D). The wide survey of both ES and $\alpha \mathrm{Fe}$-ES groups contained signals arising from the backbone of polymer scaffold, namely carbon $(\mathrm{C})$, nitrogen $(\mathrm{N})$, and oxygen (O). Signals that correspond to iron were only detected in the $\alpha \mathrm{Fe}$-ES group due to the LbL modification by $\alpha$ FeNPs (Figure 4D). Quantitative elemental surface composition of the ES and $\alpha \mathrm{Fe}$-ES was shown in Table 3. In addition, attenuated total reflectance Fourier transform infrared spectroscopy (ATR-FTIR) was performed. Compared with the ES control, $\alpha$ Fe-ES showed a peak at $1,543 \mathrm{~cm}^{-1}$, representing the typical stretching of $-\mathrm{NR}_{2}$, which was caused by the nitrogen plasma treatment (Figure S1).

Wettability was investigated using contact angle testing (Figure 4E). While the ES scaffold displayed a large contact angle of approximately $105.8^{\circ} \pm 3.56^{\circ}$, the nano assembled scaffolds displayed significantly decreased contact angles (down to approximately $0^{\circ}$ ), suggesting improved wetting properties (water affinity) and enhanced hydrophilicity. This improvement was caused by the presence of successful coating on the outer surface of the scaffolds with hydrophilic nanoparticles.

Protein adsorption was significantly increased in $\alpha \mathrm{Fe}$-ES (4.91 \pm 0.49$)$ compared with that in the ES control (3.29 \pm 0.51 , Figure $4 \mathrm{~F}, P<0.01$ ), possibly because of the increased surface area and roughness.

\section{Biological properties}

\section{Cell adhesion and cell spreading}

The adhesion and spreading behaviors of ADSCs were visualized using CLSM, as shown in Figure 5A-D. In both groups, the cells showed greater spreading at 24 hours than at 6 hours. The cells were anchored to the surface via filopodia along the electrospun fibers. Although no difference was detected in the number of adherent cells $(80.93 \pm 4.96$ for ES, and $78.38 \pm 4.87$ for $\alpha \mathrm{Fe}-\mathrm{ES}, P>0.05$, Figure $5 \mathrm{E}$ ), the cells on $\alpha \mathrm{Fe}$-ES showed substantial spreading with active cytoskeletal processes as early as 6 hours. They spread better than those on ES control at 6 hours and 24 hours. The difference was significant at 6 hours, confirming the better cell spreading on $\alpha \mathrm{Fe}-\mathrm{ES}\left(421.72 \pm 58.04 \mu \mathrm{m}^{2}\right.$ for $\mathrm{ES}$, and $641.56 \pm 79.11 \mu \mathrm{m}^{2}$ for $\alpha \mathrm{Fe}-\mathrm{ES}, P<0.01$, Figure 5F). However, this advantage was not significant at 24 hours, when 
A

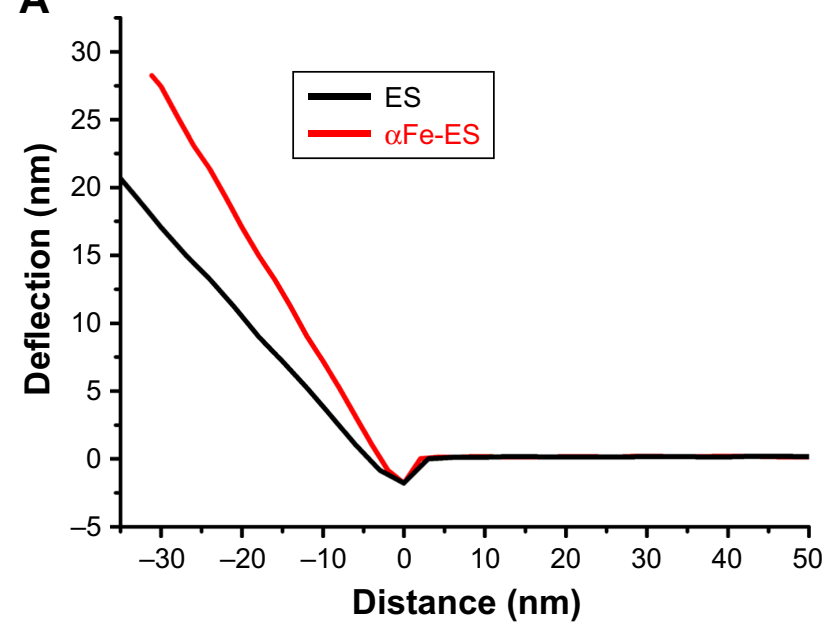

B

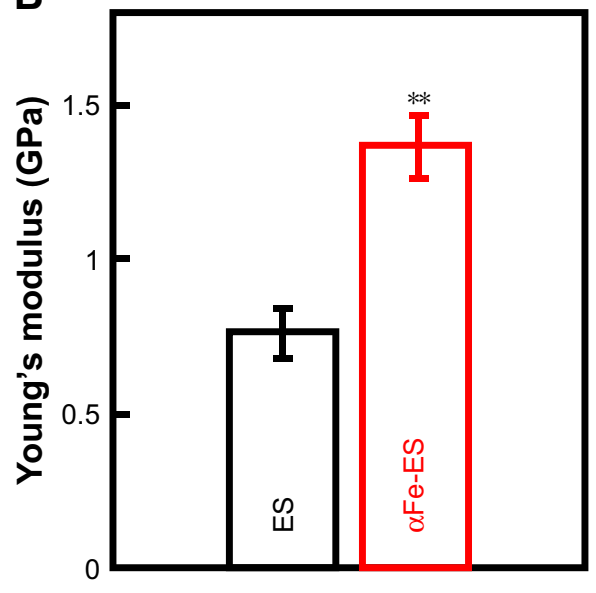

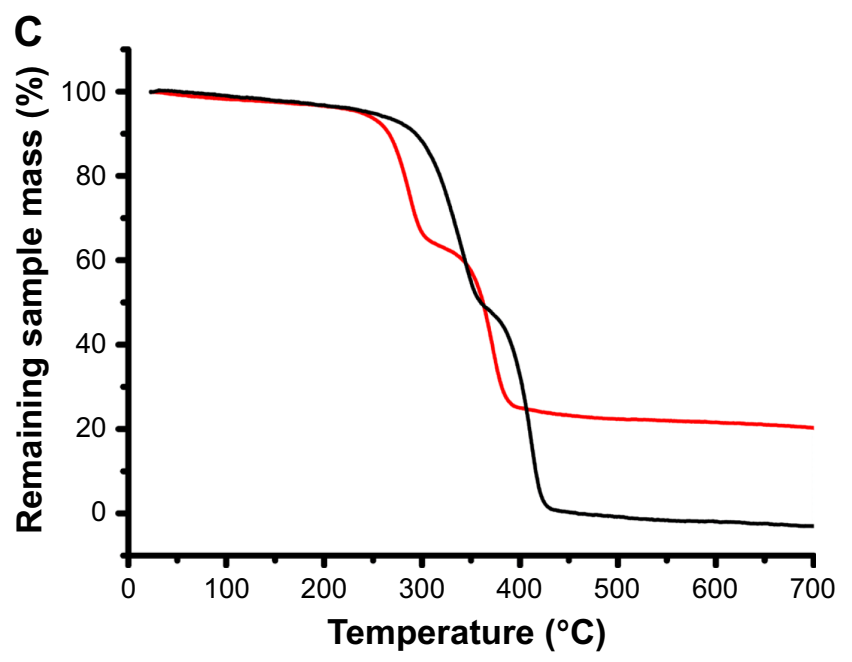

D

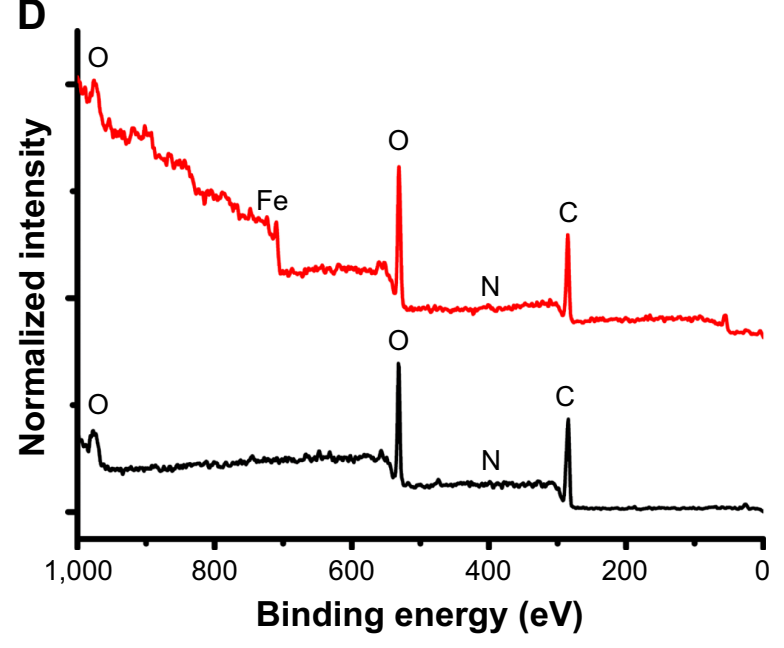

E
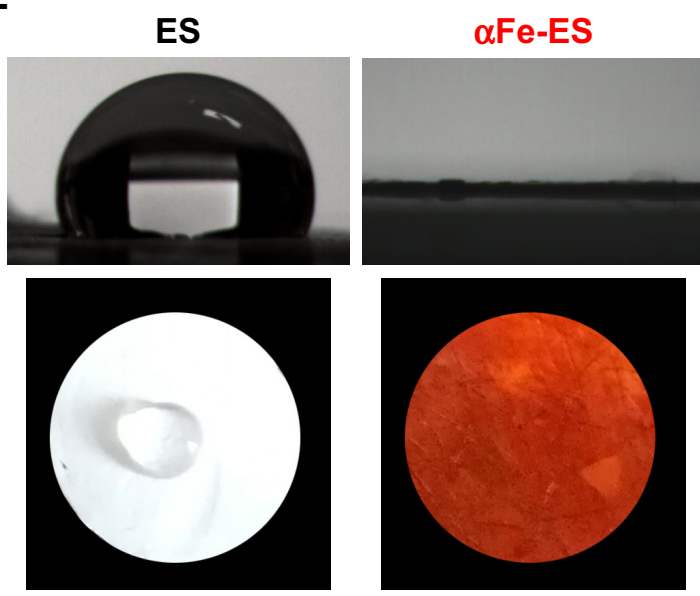

F

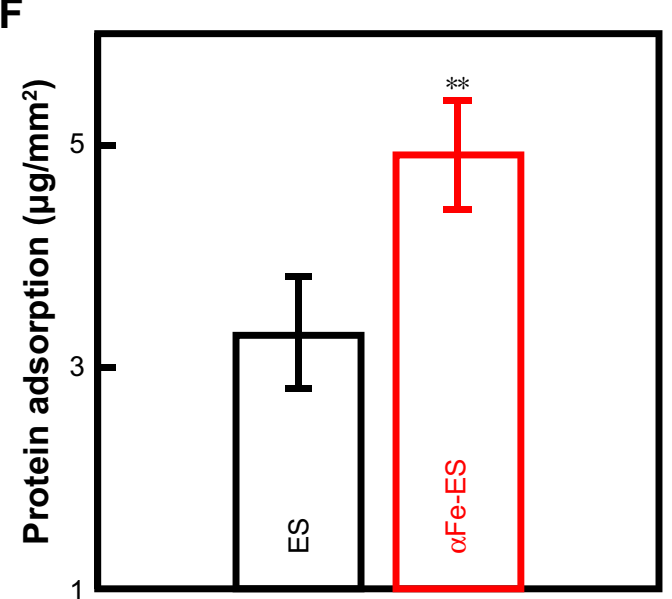

Figure 4 Physical and surface properties of the scaffolds (ES control and $\alpha F e-E S)$. (A) Representative deflection-distance curves of the electrospun scaffolds. (B) Young's modulus of $E S$ and $\alpha F e-E S$ by nano indentation $(n=4)$. (C) TGA results of the samples' weight loss during thermal treatment. (D) XPS spectra of the two groups. (E) Water contact angles of the two groups. (F) Measurements of protein adsorption $(n=9)$.

Note: $* * P<0.01$.

Abbreviations: $\alpha F e N P$, hydrophilic hematite nanoparticle; $\alpha \mathrm{Fe}-\mathrm{ES}, \alpha \mathrm{FeNPs}$-assembled electrospun scaffold; ES, untreated electrospun scaffold; TGA, thermogravimetric analysis; XPS, X-ray photoelectron spectroscopy. 
Table 3 Elemental surface composition (in atomic percentage (\%)) of the ES and $\alpha \mathrm{Fe}-\mathrm{ES}$ determined by XPS (mean $\pm \mathrm{SD}$, three measurements).

\begin{tabular}{l|l|l|l|l}
\hline Sample & C Is (\%) & N Is (\%) & O Is (\%) & Fe 2 p (\%) \\
\hline ES control & $66.61 \pm 1.07$ & $1.78 \pm 0.09$ & $31.61 \pm 0.12$ & 0 \\
$\alpha$ Fe-ES & $55.4 I \pm 0.94$ & $1.66 \pm 0.08$ & $38.85 \pm 0.11$ & $4.08 \pm 0.05$ \\
\hline
\end{tabular}

Abbreviations: $\alpha \mathrm{Fe}-\mathrm{ES}, \alpha \mathrm{FeNPs}$-assembled electrospun scaffold; ES, untreated electrospun scaffold; XPS, X-ray photoelectron spectroscopy. cells on both groups were well spread, most of which were spindle-shaped. Therefore, the initial spreading of ADSCs was significantly improved in $\alpha \mathrm{Fe}-\mathrm{ES}$.

\section{Cell proliferation}

Cell morphology after 2 days seeding on the scaffolds is shown in Figure 6A and B. The results were consistent with the CLSM
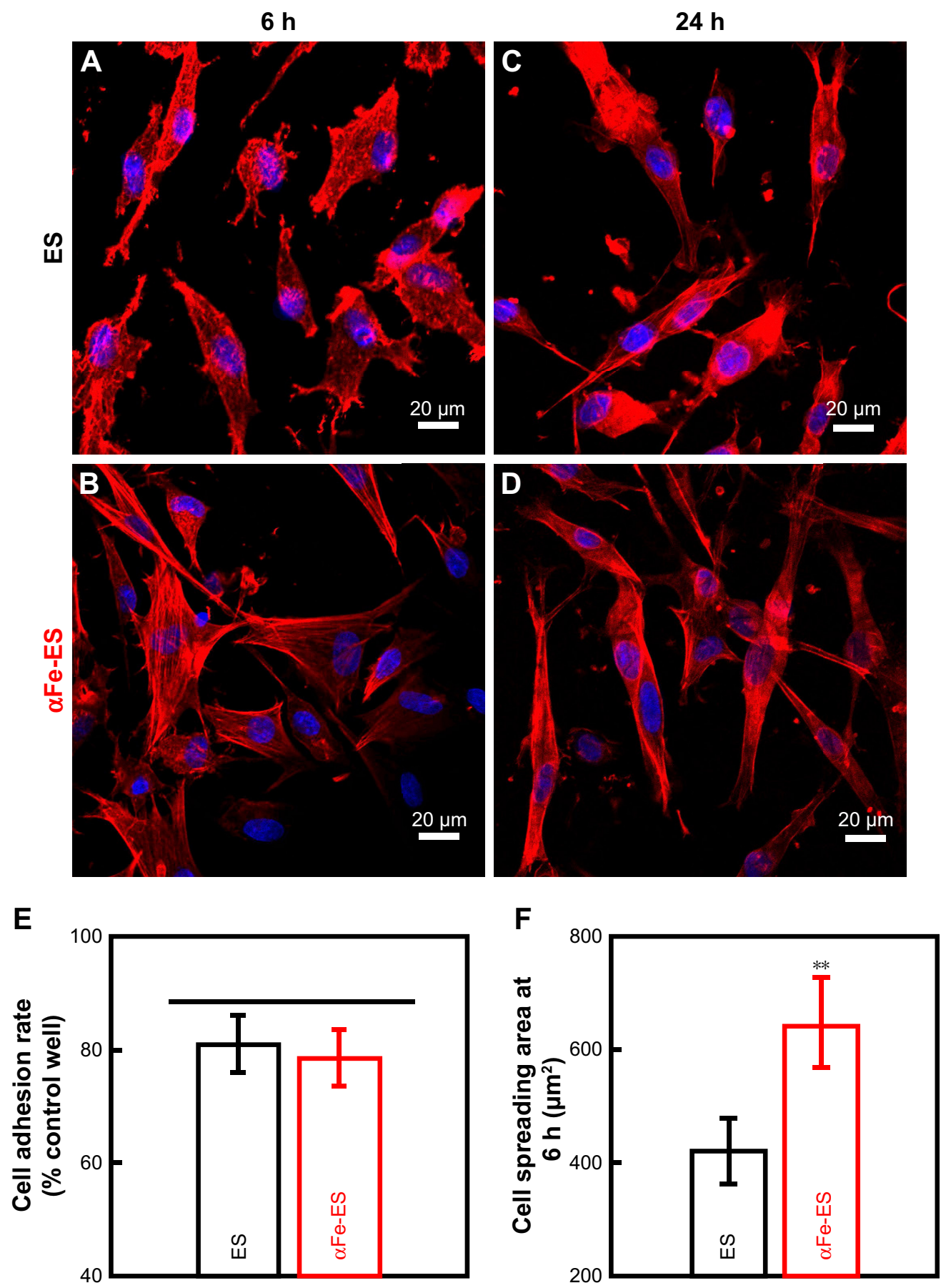

Figure 5 Confocal laser scanning microscopy images $(\times 400)$ of morphology of ADSCs cultured on the scaffolds (ES control and $\alpha F e-E S)$ at 6 hours $($ A, B) and 24 hours (C, D). Cells were stained for F-actin (red) and the nucleus (blue). (E) Quantitative analysis of adhered cell ratio at 6 hours. (F) Quantitative analysis of cell spreading area at 6 hours. Note: $* * P<0.01$.

Abbreviations: ADSC, adipose-derived stem cell; $\alpha$ FeNP, hydrophilic hematite nanoparticle; $\alpha$ Fe-ES, $\alpha$ FeNPs-assembled electrospun scaffold; ES, untreated electrospun scaffold. 
images, presenting as well spread cells in both groups. The ADSCs showed a homogenous and fast three-dimensional ingrowth into the nanocomposite, as well as into the control scaffolds. However, the cells on the nano assembled scaffolds seemed to show better cell-fiber entanglement, perhaps because of the better surface properties and the presence of the nanoparticles providing more cell adhesion sites.

Proliferation of ADSCs cultured on the two scaffolds was assessed via changes in OD using a CCK-8 kit (Figure 6C). Cell numbers were increased from 1 to 10 days in both groups. The cells proliferated slowly over the first 4 days, after which the growth rate greatly increased. However, no differences were detected at any time point between the two groups $(P>0.05)$. The results indicated that the $\alpha$ Fe-ES neither promoted nor hindered the proliferation of the seeded stem cells compared with ES.

A

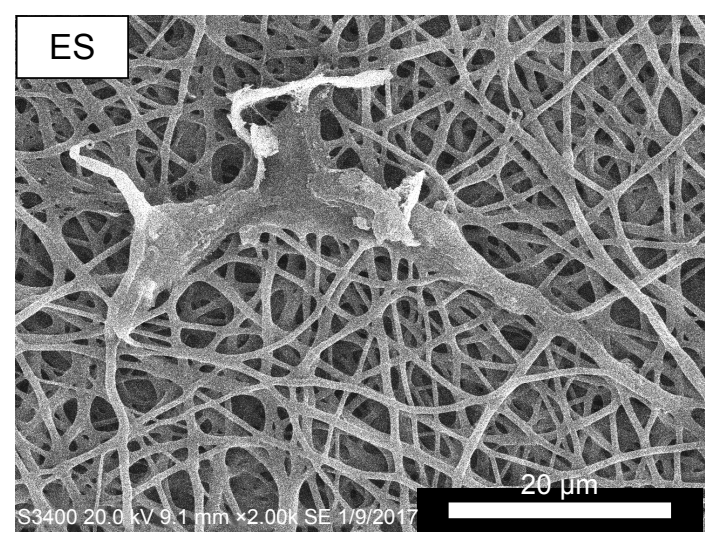

C

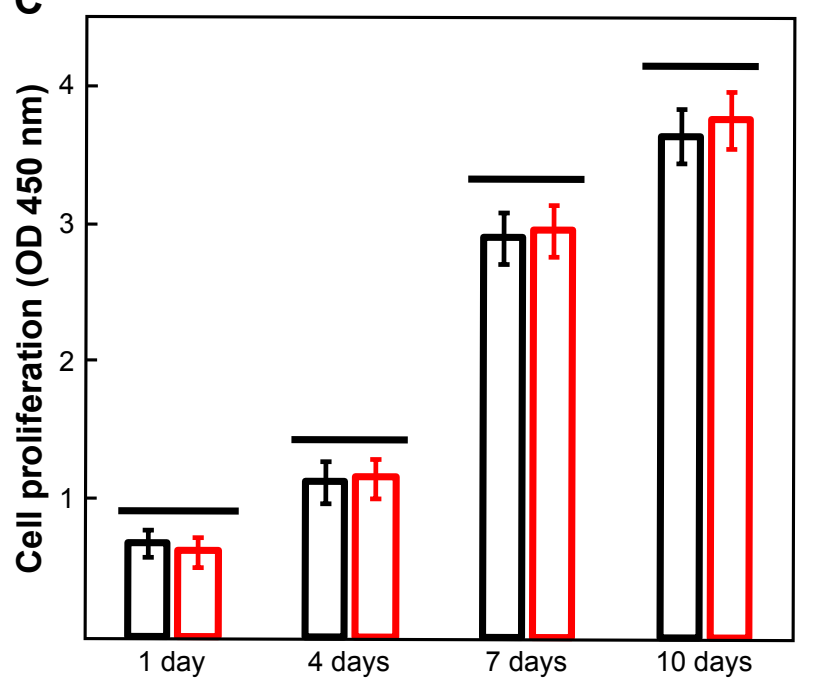

1 day

10 days
B

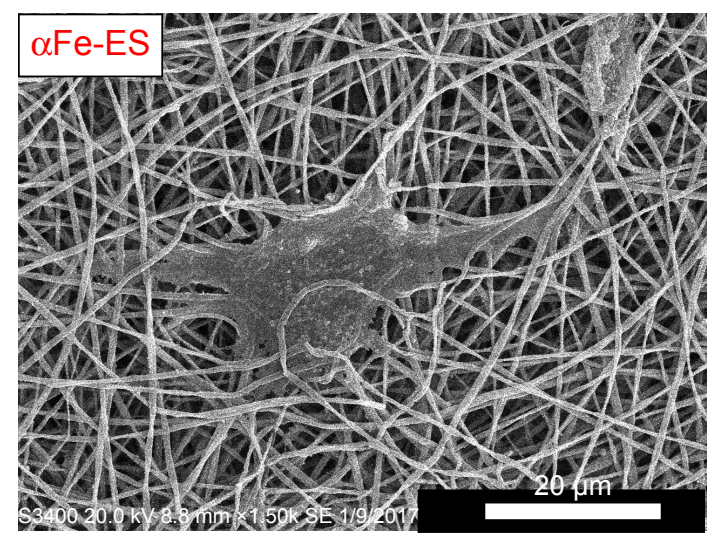

D

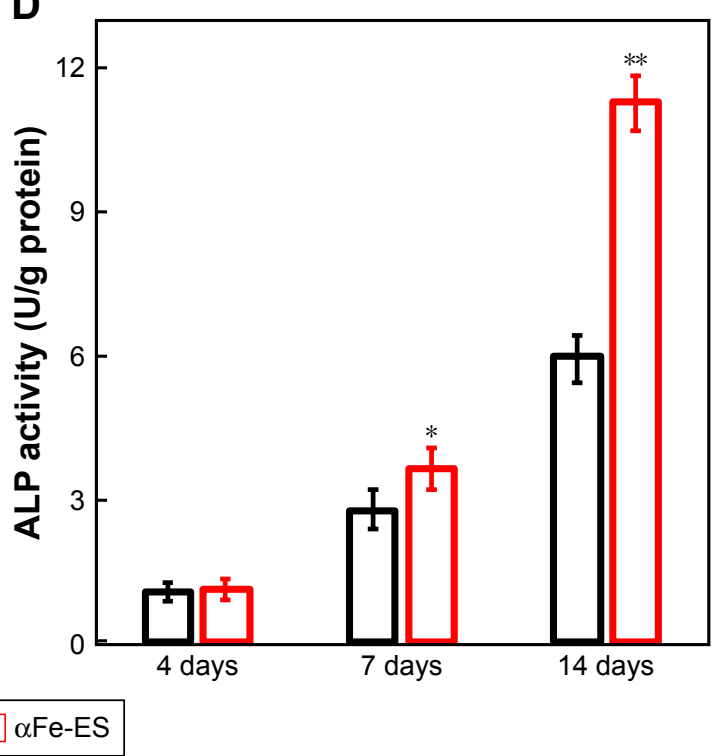

Figure 6 Cell morphology and ALP activity of ADSCs cultured on the scaffolds. Cell morphology on the scaffolds by SEM at 2 days after seeding on ES (A) and $\alpha$ Fe-ES (B). (C) Cell proliferation on ES and $\alpha$ Fe-ES. (D) ALP activities of seeded cells at 4, 7, and I4 days after seeding $(n=4)$.

Note: $* P<0.05, * * P<0.01$.

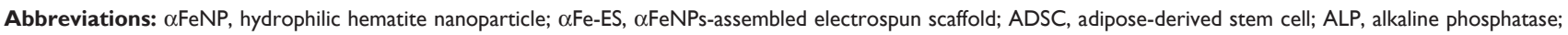
ES, untreated electrospun scaffold; OD, optical density; SEM, scanning electron microscopy. 

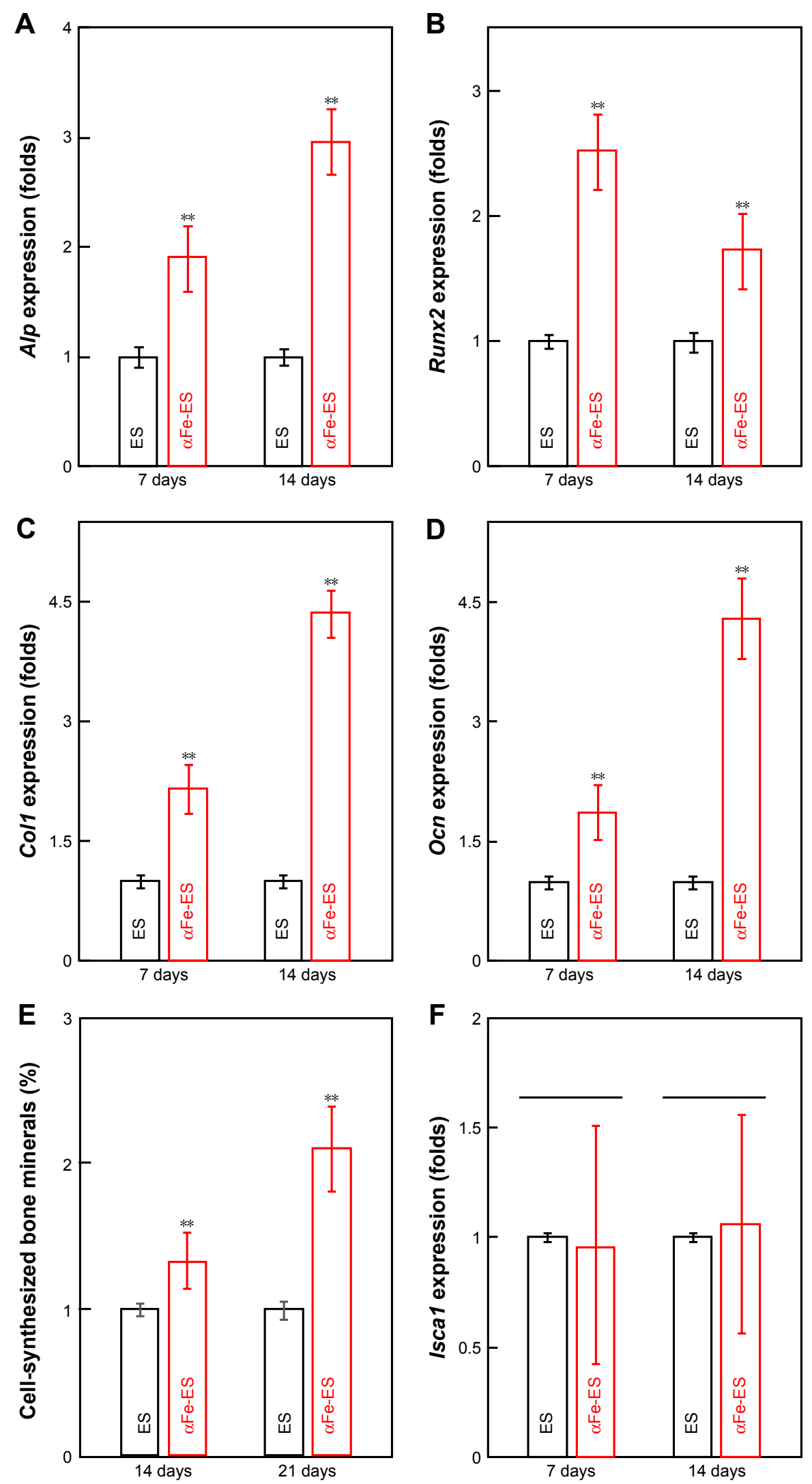

Figure 7 Osteogenic gene expression and mineral synthesis of ADSCs on the scaffolds. (A-D) The expressions of Alp, Coll, Runx2, and Ocn on the scaffolds after 7 days and 14 days of culture $(n=4)$. (E) Quantitative analysis of mineral synthesis by the cells after I4 days and $2 I$ days of culture $(n=6)$. (F) The expressions of Iscal on the scaffolds after 7 days and 14 days of culture $(n=4)$.

Note: $* * P<0.01$.

Abbreviations: $\alpha$ FeNP, hydrophilic hematite nanoparticle; $\alpha \mathrm{Fe}-\mathrm{ES}, \alpha \mathrm{FeNPs}$-assembled electrospun scaffold; ADSC, adipose-derived stem cell; Alp, alkaline phosphatase; Coll, collagen type I; ES, untreated electrospun scaffold; Iscal, iron-sulfur cluster assembly protein I; Ocn, osteocalcin; Runx2, runt related transcription factor 2. 

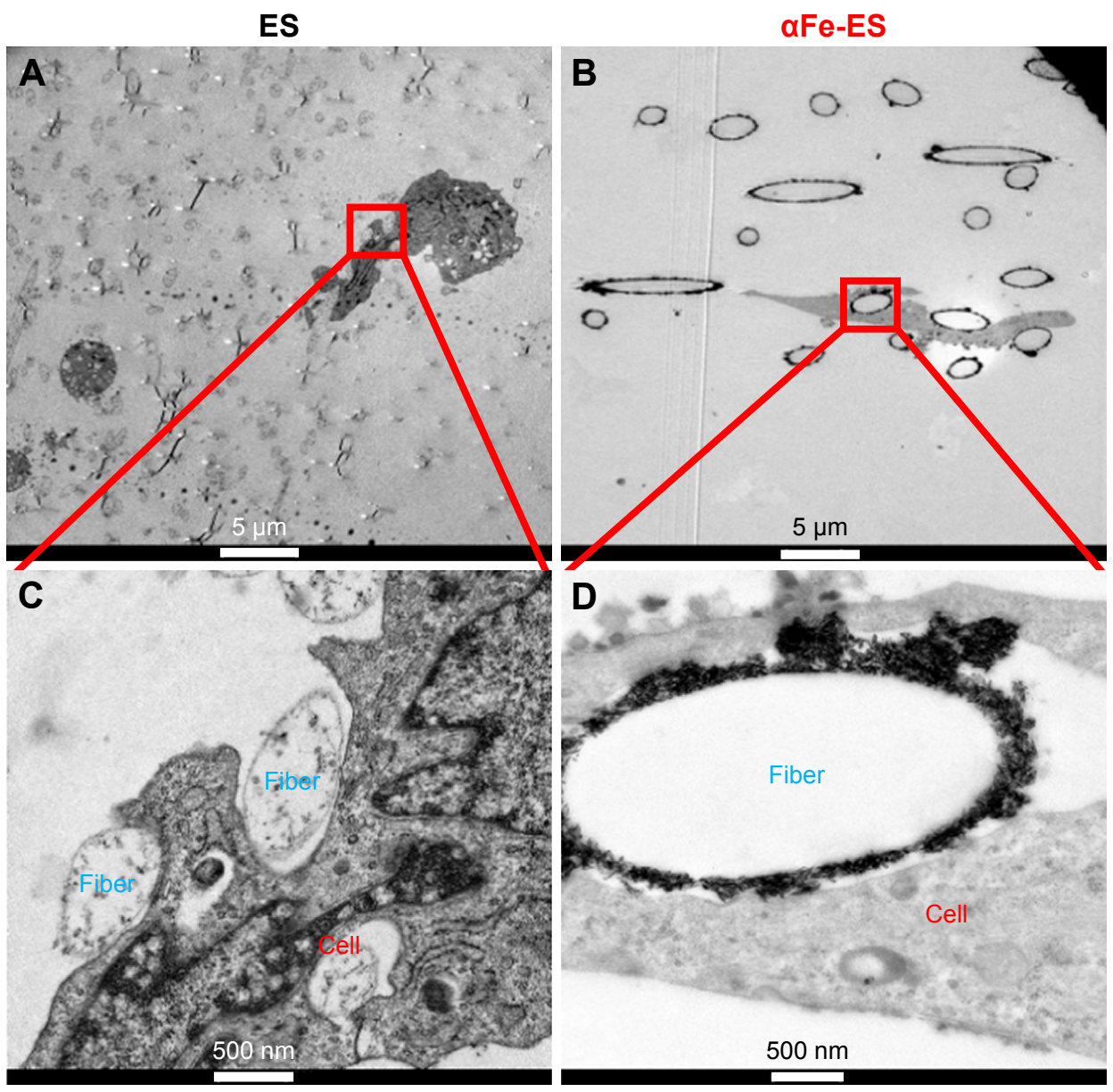

Figure 8 The nano interface provided better adhesion sites for the cells. High magnification TEM images of ADSCs after 7 days' culture on the scaffolds, (A and C) ES, (B and D) $\alpha$ Fe-ES. A few $\alpha$ FeNPs were seen inside the cells.

Abbreviations: $\alpha$ FeNP, hydrophilic hematite nanoparticle; $\alpha \mathrm{Fe}-\mathrm{ES}, \alpha \mathrm{FeNPs}$-assembled electrospun scaffold; ADSC, adipose-derived stem cell; ES, untreated electrospun scaffold; TEM, transmission electron microscopy.

points, reaching nearly 2-fold of that on the ES control at 21 days.

Expression levels of Iscal, which is regarded as a magnetosensing protein, were also detected at 7 days and 14 days (Figure 7F). However, there was no difference between $\alpha$ Fe-ES and ES at both time points $(P>0.05)$.

\section{Interaction of ADSCs with the scaffold surface}

TEM was performed to detect the interaction of ADSCs with the scaffold surface (Figure 8 ). The nano assemblies appeared to provide better sites for cell adhesion (Figure 8B and D) compared with ES control (Figure 8A and C). A few nanoparticles were observed to be internalized into the cells.

\section{Discussion}

According to the previous studies, specific differentiation of stem cells can be tailored by altering the surface properties of the biomaterials, such as the surface chemical composition, structure, and mechanical properties. ${ }^{40,41}$ In the current study, $\alpha$ FeNPs electrospun scaffolds were coated with $\alpha$ FeNPs using the LbL technique with the hypothesis that the assemblies could work as a bioactive interface with micro-scale surface topography and increased matrix rigidity. Therefore, the new nano scaffold could have enhanced osteoinduction capacities, and better performance in bone tissue engineering.

In vitro cell assays using ADSCs as seed cells were performed. Enhanced cellular performance was detected in the nano assembled scaffolds compared with the unmodified scaffolds, including better cell spreading; improved osteogenic differentiation, demonstrated as substantial increases in ALP activity and osteogenic gene expression; and a 2-fold increase in bone matrix mineral synthesis. Efforts were made to explore the underlying mechanisms, and the general mechanism is illustrated in Figure 9. The different surface properties aroused different stimuli to the cells. Therefore, the cells responded differently. These were consistent with previous reports. ${ }^{9} 10,12,19$ 


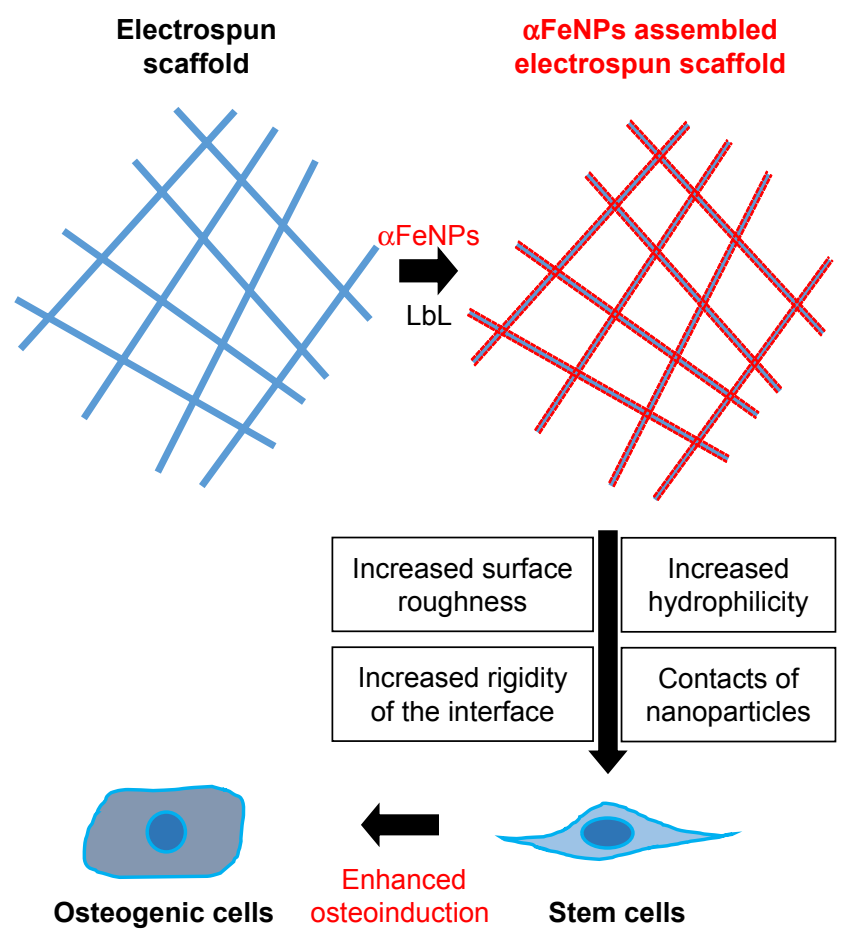

Figure 9 Schematic illustration of the mechanisms for enhancing osteogenic differentiation of ADSCs using electrospun scaffolds with assemblies of functional IONP through the LbL process.

Abbreviations: $\alpha$ FeNP, hydrophilic hematite nanoparticle; ADSC, adipose-derived stem cell; IONP, iron oxide nanoparticle; LbL, Layer-by-Layer.

Magnetism was not an influencing factor here, as indicated by the results shown in Figures $1 \mathrm{~B}$ and $7 \mathrm{~F}$. $\alpha \mathrm{FeNPs}$ showed very weak magnetic behavior, which is consistent with previous reports. ${ }^{30,31} \mathrm{It}$ is reasonable that $\alpha \mathrm{Fe}-\mathrm{ES}$, whose main body was a polymer and only the surface was decorated with some $\alpha$ FeNPs, did not show detectable magnetic behavior under the current conditions by VSM. However, the improved cellular performance on the $\alpha \mathrm{Fe}$-ES were attributed to the three major reasons based on the obtained results. First, the increased hydrophilicity and surface roughness of the nano assembled scaffolds. Numerous studies have demonstrated that enhanced surface roughness and surface hydrophilicity could improve the biocompatibility of scaffold materials. ${ }^{42-44}$ As we found in the current study, the hydrophilicity of the scaffold was significantly improved by the assemblies of hydrophilic iron oxide nanoparticles, presented by the decreased water contact angle (Figure 4E). Similar results have been reported several times previously. ${ }^{25,45,46}$ Different from the commonly used method by adding nanomaterials directly into the matrix, Tang et $\mathrm{al}^{25}$ reported that the assembly of silica nanoparticles on the fiber surface of a polycaprolactone fibrous scaffold improved fiber wettability and surface roughness. Comparatively, the decrease in the contact angle was more obvious in this study. The reasons may lie in the excellent hydrophilicity of the DMAS-coated $\alpha \mathrm{FeNPs}$ and the complete coverage of $\alpha \mathrm{FeNP}$ assemblies around the electrospun fibers.

The improved surface hydrophilicity was also ascribed to the enhanced surface roughness derived from protrusions of the nanoparticles, which were confirmed morphologically using SEM and AFM (Figures 2 and 3). In addition, increased surface roughness and surface wettability also resulted in higher protein adsorption (Figure 4F). Enhanced surface wettability and protein adsorption capacity both arose from the modified topographical properties. In addition, hydrophilicity plays a vital role in protein adsorption, which could promote cell adhesion at an early stage. ${ }^{47}$

Second, the enhanced osteoinduction is the increased rigidity of the nano interface. The mechanical properties of the matrix are known to influence cell behavior, regardless of the protein coating of the substrate. Engler et a ${ }^{12}$ disclosed that bone mesenchymal stem cells are capable of driving themselves to osteogenic differentiation on a stiff matrix, probably via adjusting the deformation of the ECM according to the matrix elasticity. Ryan et $\mathrm{al}^{48}$ showed that cell spreading and motility are enhanced on stiff substrates in comparison to that on soft surfaces (which favor cell-cell interaction and lead to more dense cell aggregates). Therefore, the increased rigidity of the matrix, especially the cell-implant interface, is favorable for cellular osteogenic differentiation. In this study, the elastic modulus of the interface with $\alpha$ FeNPs assemblies was increased (Figure 4A and B), and more similar to that of human cancellous bone than ES control, ${ }^{49}$ which bodes well for osteoinduction. Indeed, this was confirmed by our cell test results, which showed that cell spreading (Figure 5F) and ECM synthesis of ADSCs on $\alpha$ Fe-ES (Figure 7E) were significantly enhanced compared with those on ES. The ECM plays a key role when stem cells sense and respond to the stiffness of a material surface. ${ }^{12}$ Therefore, our results indicated that the microenvironment on $\alpha \mathrm{Fe}$-ES is more conducive to stem cells osteogenic differentiation.

Furthermore, it should be interesting to discuss whether the stiffness can play a role in promoting cell differentiation into other types except bone/osteogenic cells if the elastic modulus is similar. Most of the current research studied the effects of different elastic modulus, together with different stiffness on the cell behaviors, including cell adhesion, proliferation, and differentiation. ${ }^{12,50}$ The key lies in that the matrix elasticity, not stiffness, directs the lineage specification stem cells. ${ }^{12,50}$ Because it is the intrinsic properties of the bulk material that can induce the mechanical stimuli to the cells, regardless of its extrinsic properties like thickness 
and porosity. For example, the elasticity of the matrix is better to be more than $30 \mathrm{kPa}$ for bone regeneration, and $8-17 \mathrm{kPa}$ for muscle formation. ${ }^{12,50}$ Therefore, stiffness only cannot promote the differentiation of cells into other types if the elastic modulus was similar. However, it can lead to some differences in the efficiency of inducing differentiation. Cell proliferation can be influenced by the thickness of the nanofibrous scaffold. ${ }^{51}$ Thicker scaffolds are a better substrate than thinner ones due to the better stability in dimension. ${ }^{51}$ In addition, different porosity can affect cell differentiation. ${ }^{50}$ Relatively smaller pore size leads to better differentiation because the cells can attach in three-dimensions, and the force developed will be smaller than in the condition of big pores. ${ }^{50}$

Third, the cell contacts of nanoparticles on the nano interface, as proved by Figure 8 . The interaction between the nanomaterials and the cells has been considered in recent studies because the physical and chemical properties of nanomaterials strongly influence the biochemical properties of cells while they are in contact with each other. The nanoparticles can play a protein-like role ${ }^{52}$ like RGD (Arg-Gly-Asp) peptides, working as cell adhesion sites. The differentiation process may be triggered by the contact of ADSC with nanoparticles on the surface of the scaffolds. Liu et a ${ }^{53}$ prepared assemblies of $\gamma \mathrm{Fe}_{2} \mathrm{O}_{3}$ nanoparticles on a disk-like PLA substrate. They found that the decoration of nanoparticles on the scaffold enhanced cellular adhesion and growth by acting as cell adhesion sites. This adhesion sites-like effect of the nanoparticles was also identified in other studies. ${ }^{54,55}$ However, magnetic effects may have played an important role in these studies. In another study, Wei et $\mathrm{al}^{56}$ showed that the surface nanotopography alone can affect cellular adhesion, and switching between nanotubes and nanotips can be used to direct stem cell differentiation. Although the magnetism was not attributed as an influencing factor here (Figures $1 \mathrm{~B}$ and 7F), LbL assembly of $\alpha$ FeNPs on the scaffold achieved enhanced the cellular osteogenic differentiation of ADSCs (Figures 6D and 7A-E). The underlying mechanism still needs further study. Furthermore, how to magnify the effect of surface topographic cues with other effects, such as magnetic stimulation, on osteogenic differentiation of stem cells would be of substantial interest.

The surface properties of the biomaterials have a crucial role in the cell-implant interactions at the implant/tissue interface. ${ }^{40}$ As stated above, the enhanced surface mechanical properties, nanostructure fabrication, and $\alpha$ FeNPs incorporation were simultaneously achieved on $\alpha \mathrm{Fe}-\mathrm{ES}$. Therefore, it is highly possible that the increased surface roughness, wettability, and matrix rigidity had a synergistic effect to enhance effects of $\alpha \mathrm{Fe}$-ES on the cytoskeletal organization and osteogenic differentiation of ADSCs in vitro.

Compared with previous studies, the current work assembled the nanoparticles into a dense and uniform granular layer. The assemblies can stimulate cells by changing the mechanical properties of the interface. Moreover, the assembled film of $\alpha$ FeNPs can provide additional capabilities to the composites, such as providing better cell adhesion sites. As observed in this study, the adhered cells spread better on the rough and hydrophilic nano-assembled scaffold, but they were not increased in the cell numbers. It may be due to the cells like the hydrophilic scaffold, and the cell protrusions could easily and firmly catch the assemblies of $\alpha$ FeNPs. Anyway, important markers related to cellular adhesion, including integrin and cadherin, will be detected in our further study.

$\alpha$ FeNPs are biocompatible to human keratinocytes and human dental pulp stem cells. ${ }^{57,58}$ However, there are only several published papers concerning the application of $\alpha F e N P s$ in bone tissue engineering, ${ }^{33,43}$ let alone its effects on cell adhesion and proliferation, because the focus of the research is on their counterpart, superparamagnetic iron oxide nanoparticles (mainly $\gamma \mathrm{Fe}_{2} \mathrm{O}_{3}$ and $\mathrm{Fe}_{3} \mathrm{O}_{4}$ ). ${ }^{26-28,43}$ Therefore, the current study represents a new way to apply nanomaterials in bone tissue engineering. Determining the detailed molecular pathways and in vivo animal testing are needed for further verification before this method can be applied clinically.

\section{Conclusion}

LbL is an effective method to coat the outer surface of electrospun scaffolds with nanoparticle assemblies. The $\alpha$ FeNPs assemblies on the porous electrospun scaffolds improved the hydrophilicity and surface roughness, and increased the elastic modulus of the interface between the scaffolds and cells, ultimately enhancing the osteoinduction capacities of the scaffolds. Therefore, the results suggested that constructing a bioactive interface by LbL assembly using $\alpha$ FeNPs is a promising method for bone tissue engineering.

\section{Acknowledgments}

This work was supported by the National Natural Science Foundation of China (grant number 81771044 and 81800937), the Jiangsu Medical Youth Talent (grant number QNRC2016853), the Southeast University-Nanjing Medical University Cooperative Research Project (grant number 2242018K3DN16), Qing Lan Project, and the Project of the Priority Academic Program Development of Jiangsu Higher Education Institutions (grant number 2018-87). 


\section{Author contributions}

Jianfei Sun and Yang Xia both conceived the project and wrote the manuscript. Jianfei Sun and Yang Xia designed the experiments. Shanshan Ma and Zibin Wang performed the fabrication and the characterization of the scaffolds. Peng Wang prepared the nanoparticles. Shanshan Ma, Yu Guo, and Zukun Yang carried out the cell culture, cell activity test, and captured the CLSM images. Liping Han performed the statistical analysis. Zibin Wang performed the TEM. All authors contributed to data analysis, drafting and revising the article, gave final approval of the version to be published, and agree to be accountable for all aspects of the work.

\section{Disclosure}

The authors report no conflicts of interest in this work.

\section{References}

1. Diomede F, D'Aurora M, Gugliandolo A, et al. A novel role in skeletal segment regeneration of extracellular vesicles released from periodontalligament stem cells. Int J Nanomedicine. 2018;13:3805-3825.

2. Diomede F, Gugliandolo A, Cardelli P, et al. Three-dimensional printed PLA scaffold and human gingival stem cell-derived extracellular vesicles: a new tool for bone defect repair. Stem Cell Res Ther. 2018;9(1):104.

3. Ni P, Fu S, Fan M, et al. Preparation of poly(ethylene glycol)/polylactide hybrid fibrous scaffolds for bone tissue engineering. Int J Nanomedicine. 2011;6:3065-3075.

4. Wang Y, Guo G, Chen H, et al. Preparation and characterization of polylactide/poly( $\varepsilon$-caprolactone)-poly(ethylene glycol)-poly( $\varepsilon$ caprolactone) hybrid fibers for potential application in bone tissue engineering. Int J Nanomedicine. 2014;9:1991-2003.

5. Chen S, Jian Z, Huang L, et al. Mesoporous bioactive glass surface modified poly(lactic-co-glycolic acid) electrospun fibrous scaffold for bone regeneration. Int J Nanomedicine. 2015;10:3815-3827.

6. Venugopal J, Ramakrishna S. Applications of polymer nanofibers in biomedicine and biotechnology. Appl Biochem Biotechnol. 2005;125(3): $147-158$.

7. Amini AR, Laurencin CT, Nukavarapu SP. Bone tissue engineering: recent advances and challenges. Crit Rev Biomed Eng. 2012;40(5): 363-408.

8. Xia Y, Yao J, Li N, et al. Electrospun poly(butylene carbonate) membranes for guided bone regeneration: In vitro and in vivo studies. J Bioactive Comp Polymers. 2014;29(5):486-499.

9. Chen G, Xia Y, Lu X, Zhou X, Zhang F, Gu N. Effects of surface functionalization of PLGA membranes for guided bone regeneration on proliferation and behavior of osteoblasts. J Biomed Mater Res A. 2013;101(1):44-53.

10. Chen H, Qian Y, Xia Y, et al. Enhanced osteogenesis of ADSCs by the synergistic effect of aligned fibers containing collagen I. ACS Appl Mater Interfaces. 2016;8(43):29289-29297.

11. Mozumder MS, Mairpady A, Mourad AI. Polymeric nanobiocomposites for biomedical applications. J Biomed Mater Res B Appl Biomater. 2017;105(5):1241-1259.

12. Engler AJ, Sen S, Sweeney HL, Discher DE. Matrix elasticity directs stem cell lineage specification. Cell. 2006;126(4):677-689.

13. González-García C, Moratal D, Oreffo RO, Dalby MJ, SalmerónSánchez M. Surface mobility regulates skeletal stem cell differentiation. Integr Biol. 2012;4(5):531-539.

14. Huebsch N, Arany PR, Mao AS, et al. Harnessing traction-mediated manipulation of the cell/matrix interface to control stem-cell fate. Nat Mater. 2010;9(6):518-526.
15. Gao X, Zhang X, Song J, et al. Osteoinductive peptide-functionalized nanofibers with highly ordered structure as biomimetic scaffolds for bone tissue engineering. Int J Nanomedicine. 2015;10:7109-7128.

16. Wang DX, He Y, Bi L, et al. Enhancing the bioactivity of Poly(lacticco-glycolic acid) scaffold with a nano-hydroxyapatite coating for the treatment of segmental bone defect in a rabbit model. Int J Nanomedicine. 2015;8:1855-1865.

17. Qian YZ, Chen HB, Xu Y, et al. The preosteoblast response of electrospinning PLGA/PCL nanofibers: effects of biomimetic architecture and collagen I. Int J Nanomedicine. 2015;11:4157-4171.

18. Sengupta P, Surwase SS, Prasad BLV. Modification of porous polyethylene scaffolds for cell attachment and proliferation. Int J Nanomedicine. 2015;13:87-90.

19. Lu T, Wen J, Qian S, et al. Enhanced osteointegration on tantalumimplanted polyetheretherketone surface with bone-like Elastic modulus. Biomaterials. 2015;51:173-183.

20. Hu X, Park SH, Gil ES, et al. The influence of elasticity and surface roughness on myogenic and osteogenic-differentiation of cells on silkelastin biomaterials. Biomaterials. 2011;32(34):8979-8989.

21. Seidi A, Ramalingam M, Elloumi-Hannachi I, Ostrovidov S, Khademhosseini A. Gradient biomaterials for soft-to-hard interface tissue engineering. Acta Biomater. 2011;7(4):1441-1451.

22. An J, Chua CK, Yu T, Li H, Tan LP. Advanced nanobiomaterial strategies for the development of organized tissue engineering constructs. Nanomedicine. 2013;8(4):591-602.

23. Kelleher CM, Vacanti JP. Engineering extracellular matrix through nanotechnology. J R Soc Interface. 2010;7(Suppl 6):S717-S729.

24. Richardson JJ, Björnmalm M, Caruso F. Multilayer assembly. Technology-driven layer-by-layer assembly of nanofilms. Science. 2015;348(6233):aaa2491.

25. Tang Y, Zhao Y, Wang X, Lin T. Layer-by-layer assembly of silica nanoparticles on 3D fibrous scaffolds: enhancement of osteoblast cell adhesion, proliferation, and differentiation. $J$ Biomed Mater Res A. 2014;102(11):3803-3812

26. Hu S, Zhou Y, Zhao Y, et al. Enhanced bone regeneration and visual monitoring via superparamagnetic iron oxide nanoparticle scaffold in rats. J Tissue Eng Regen Med. 2018;12(4):e2085-e2098.

27. Wang Q, Chen B, Ma F, et al. Magnetic iron oxide nanoparticles accelerate osteogenic differentiation of mesenchymal stem cells via modulation of long noncoding RNA INZEB2. Nano Res. 2017;10(2):626-642.

28. Wang Q, Chen B, Cao M, et al. Response of MAPK pathway to iron oxide nanoparticles in vitro treatment promotes osteogenic differentiation of hBMSCs. Biomaterials. 2016;86:11-20.

29. Henstock JR, Rotherham M, Rashidi H, Shakesheff KM, El Haj AJ. Remotely activated mechanotransduction via magnetic nanoparticles promotes mineralization synergistically with bone morphogenetic protein 2: applications for injectable cell therapy. Stem Cells Transl Med. 2014;3(11):1363-1374.

30. Machala L, Tuček J, Zbořll R. Polymorphous transformations of nanometric iron (III) oxide: a review. Chem Mater. 2011;23(14):3255-3272.

31. Teja AS, Koh PY. Synthesis, properties, and applications of magnetic iron oxide nanoparticles. Prog Crystal Growth Characterization Mater. 2009;55(1-2):22-45.

32. Rufus A, Sreeju N, Philip D. Synthesis of biogenic hematite $\left(\alpha-\mathrm{Fe}_{2} \mathrm{O}_{3}\right)$ nanoparticles for antibacterial and nanofluid applications. $R S C$ Advances. 2016;6(96):94206-94217.

33. Vlad MD, del Valle LJ, Barracó M, et al. Iron oxide nanoparticles significantly enhances the injectability of apatitic bone cement for vertebroplasty. Spine. 2008;33(21):2290-2298.

34. Mizuno H, Tobita M, Uysal AC. Concise review: adipose-derived stem cells as a novel tool for future regenerative medicine. Stem Cells. 2012;30(5):804-810.

35. Sun J, Su Y, Wang C, Gu N. The investigation of frequency response for the magnetic nanoparticulate assembly induced by time-varied magnetic field. Nanoscale Res Lett. 2011;6(1):453.

36. Cleveland JP, Manne S, Bocek D, Hansma PK. A nondestructive method for determining the spring constant of cantilevers for scanning force microscopy. Rev Sci Instrum. 1993;64(2):403-405. 
37. Nikkhah M, Strobl JS, Schmelz EM, Agah M. Evaluation of the influence of growth medium composition on cell elasticity. J Biomech. 2011;44(4):762-766.

38. Zhang N, Weir MD, Chen C, et al. Orthodontic cement with proteinrepellent and antibacterial properties and the release of calcium and phosphate ions. J Dent. 2016;50:51-59.

39. Perez RA, Patel KD, Kim HW. Novel magnetic nanocomposite injectables: calcium phosphate cements impregnated with ultrafine magnetic nanoparticles for bone regeneration. RSC Adv. 2015;5(18): 13411-13419.

40. Nel AE, Mädler L, Velegol D, et al. Understanding biophysicochemical interactions at the nano-bio interface. Nat Mater. 2009;8(7):543-557.

41. Discher DE, Mooney DJ, Zandstra PW. Growth factors, matrices, and forces COMBINE and control stem cells. Science. 2009;324(5935): $1673-1677$.

42. Xia Y, Chen H, Zhang F, et al. Gold nanoparticles in injectable calcium phosphate cement enhance osteogenic differentiation of human dental pulp stem cells. Nanomedicine. 2018;14(1):35-45.

43. Xia Y, Chen H, Zhang F, et al. Injectable calcium phosphate scaffold with iron oxide nanoparticles to enhance osteogenesis via dental pulp stem cells. Artif Cells Nanomed Biotechnol. Epub 2018 Jan 21.

44. Li Y, Dai X, Bai Y, et al. Electroactive $\mathrm{BaTiO}_{3}$ nanoparticlefunctionalized fibrous scaffolds enhance osteogenic differentiation of mesenchymal stem cells. Int J Nanomedicine. 2017;12:4007-4018.

45. Lee EJ, Teng SH, Jang TS, et al. Nanostructured poly(epsiloncaprolactone)-silica xerogel fibrous membrane for guided bone regeneration. Acta Biomater. 2010;6(9):3557-3565.

46. Abdal-Hay A, Pant HR, Lim JK. Super-hydrophilic electrospun nylon-6/ hydroxyapatite membrane for bone tissue engineering. Eur Polymer J. 2013;49(6):1314-1321.

47. Takebe J, Itoh S, Okada J, Ishibashi K. Anodic oxidation and hydrothermal treatment of titanium results in a surface that causes increased attachment and altered cytoskeletal morphology of rat bone marrow stromal cells in vitro. J Biomed Mater Res. 2000;51(3):398-407.
48. Ryan PL, Foty RA, Kohn J, Steinberg MS. Tissue spreading on implantable substrates is a competitive outcome of cell-cell vs. cell-substratum adhesivity. Proc Natl Acad Sci U S A. 2001;98(8):4323-4327.

49. Morgan EF, Bayraktar HH, Keaveny TM. Trabecular bone modulusdensity relationships depend on anatomic site. J Biomech. 2003; 36(7):897-904.

50. Reilly GC, Engler AJ. Intrinsic extracellular matrix properties regulate stem cell differentiation. J Biomech. 2010;43(1):55-62.

51. Ghasemi-Mobarakeh L, Morshed M, Karbalaie K, et al. The thickness of electrospun poly (epsilon-caprolactone) nanofibrous scaffolds influences cell proliferation. Int J Artif Organs. 2009;32(3):150-158.

52. Kotov NA, Chemistry KN. Chemistry. Inorganic nanoparticles as protein mimics. Science. 2010;330(6001):188-189.

53. Liu X, Zhang J, Tang S, et al. Growth enhancing effect of LBLassembled magnetic nanoparticles on primary bone marrow cells Sci China Mater. 2016;59(11):901-910.

54. Guo Z, Hu K, Sun J, et al. Fabrication of hydrogel with cell adhesive micropatterns for mimicking the oriented tumor-associated extracellular matrix. ACS Appl Mater Interfaces. 2014;6(14):10963-10968.

55. Hu K, Zhou N, Li Y, et al. Sliced magnetic polyacrylamide hydrogel with cell-adhesive microarray interface: a novel multicellular spheroid culturing platform. ACS Appl Mater Interfaces. 2016;8(24):15113-15119.

56. Wei Y, Mo X, Zhang P, et al. Directing stem cell differentiation via electrochemical reversible switching between nanotubes and nanotips of polypyrrole array. ACS Nano. 2017;11(6):5915-5924.

57. Narayanan KB, Han SS. One-pot green synthesis of Hematite $\left(\alpha-\mathrm{Fe}_{2} \mathrm{O}_{3}\right)$ nanoparticles by ultrasonic irradiation and their in vitro cytotoxicity on human keratinocytes CRL-2310. J Clust Sci. 2016;27(5):1763-1775.

58. Xia Y, Chen HM, Hu SY, et al. Effects of nano $\alpha \mathrm{Fe}_{2} \mathrm{O}_{3}$ on the proliferation and differentiation of dental pulp stem cells. J Southeast Univ. 2018;48:165-169. Article in Chinese. 


\section{Supplementary material}

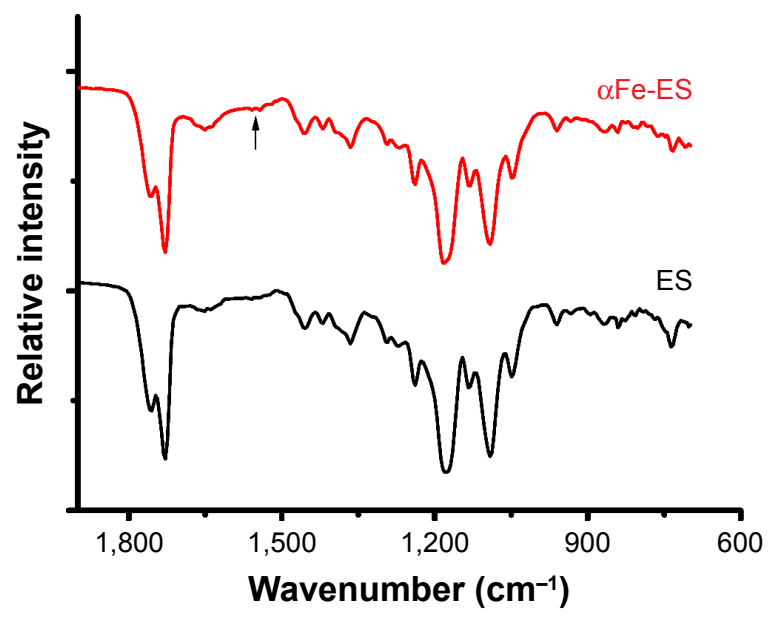

Figure SI Samples were prepared for attenuated total reflectance Fourier transform infrared spectroscopy (ATR-FTIR; NICOLET6700FT-IR, Thermo Scientific, Dallas, TX, USA) analysis.

Note: Compared with the ES control, $\alpha \mathrm{Fe}-\mathrm{ES}$ showed a peak at $1,543 \mathrm{~cm}^{-1}$, representing the typical stretching of $-\mathrm{NR}$, which was caused by the nitrogen plasma treatment. Abbreviations: $\alpha \mathrm{Fe}-\mathrm{ES}, \alpha \mathrm{FeNPs}$-assembled electrospun scaffold; ATR-FTIR, attenuated total reflectance Fourier transform infrared spectroscopy; ES, untreated electrospun scaffold.

\section{Publish your work in this journal}

The International Journal of Nanomedicine is an international, peerreviewed journal focusing on the application of nanotechnology in diagnostics, therapeutics, and drug delivery systems throughout the biomedical field. This journal is indexed on PubMed Central, MedLine, CAS, SciSearch ${ }^{\circledR}$, Current Contents ${ }^{\circledR} /$ Clinical Medicine,
Journal Citation Reports/Science Edition, EMBase, Scopus and the Elsevier Bibliographic databases. The manuscript management system is completely online and includes a very quick and fair peer-review system, which is all easy to use. Visit http://www.dovepress.com/ testimonials.php to read real quotes from published authors. 